\title{
Occurrence and Severity of Oral Mucositis in Brazilian Pediatric Cancer Patients
}

\author{
Hévila de Figueiredo Pires ${ }^{1}\left(\mathbb{D}\right.$, Paula Maria Maracajá Bezerra ${ }^{2}\left({ }^{D}\right.$, Victor Borges da Silva ${ }^{3}$, Isabella \\ Lima Arrais Ribeiro ${ }^{4}$, Eliane Batista Medeiros Serpa ${ }^{5}$, Simone Alves de Sousa ${ }^{5}$, Ana Maria \\ Gondim Valenças ${ }^{3}$
}

${ }^{1}$ Private Practice, João Pessoa, PB, Brazil.

${ }^{2}$ Postgraduate Program in Dentistry, School of Dentistry, Federal University of Paraíba, João Pessoa, PB, Brazil.

${ }^{3}$ Department of Statistics, Federal University of Paraíba, João Pessoa, PB, Brazil.

${ }^{4}$ Post-Doctoral Fellow, São Paulo University, Ribeirão Preto, SP, Brazil.

${ }^{5}$ Department of Clinical and Social Dentistry, Federal University of Paraíba, João Pessoa, PB, Brazil.

Author to whom correspondence should be addressed: Ana Maria Gondim Valença, Rua Miguel Satyro, 350, apt. 2301, Cabo Branco, João Pessoa, PB, Brazil. 58045-1 10. Phone: +55 83 999864397. E-mail: anamvalenca@gmail.com.

Academic Editors: Alessandro Leite Cavalcanti and Wilton Wilney Nascimento Padilha

Received: 27 January 2020 / Accepted: 08 May 2020 / Published: 20 May 2020

How to cite this article: Pires HF, Bezerra PMM, Silva VB, Ribeiro ILA, Serpa EBM, Sousa SA, et al. Occurrence and severity of oral mucositis in Brazilian pediatric cancer patients. Pesqui Bras Odontopediatria Clín Integr. 2020; 20 :e5621. https://doi.org/10.1590/pboci.2020.085

\begin{abstract}
Objective: To determine the occurrence and severity of oral mucositis $(\mathrm{OM})$ and the factors associated with the onset of severe oral mucositis (SOM) in pediatric cancer patients. Material and Methods: This was a longitudinal and prospective study with 85 children and adolescents (aged 0 to 19 years) admitted to the Pediatric Oncology Sector of Napoleão Laureano Hospital between November 2016 and July 2019. The patients' sociodemographic and epidemiological information, as well as hematological and biochemical parameters, were obtained from their medical charts. The oral mucosa of study participants was assessed through the modified Oral Assessment Guide (OAG) at baseline and after the 2nd, 5th and 10th week of antineoplastic treatment. Data were analyzed by Chi-square test to determine the factors associated with the occurrence of SOM $(\mathrm{p}<0.05)$. Results: The occurrence of OM was more frequent in the 2 nd $(60 \%), 5$ th $(40.9 \%)$ and 10 th week $(43.2 \%)$ of antineoplastic treatment. During the follow-up period, SOM was more frequent in the 5 th week $(34.7 \%)$, followed by the 2 nd $(32.3 \%)$ and 1 oth weeks $(29.7 \%)$. There was no association between the occurrence of SOM and the patient's age, type of tumor, chemotherapy regimen, and hematological and biochemical parameters. Conclusion: The occurrence of oral mucositis in pediatric cancer patients was significant, especially in the 2nd week of antineoplastic treatment. Severe oral mucositis was more prevalent in the 5 th week of treatment and was not associated with any of the study variables.
\end{abstract}

Keywords: Oncology Service, Hospital; Pediatrics; Mucositis; Oral Health. 


\section{Introduction}

In Brazil, cancer is the leading cause of death from illness among children and adolescents aged 1 to 19 years. Leukemias, tumors of the central nervous system (CNS) and lymphomas are among the most incident neoplasms in childhood [1,2]. While the antineoplastic treatment has been consistently optimized, drugrelated complications may still occur, including mucositis, xerostomia, dysfunction of the salivary glands, and fungal or viral infections $[3,4]$. The high incidence of oral manifestations resulting from the antineoplastic treatment can be explained by the fact that chemotherapy, the treatment of choice for childhood cancer, primarily affects sites with high cell turnover, such as the oral mucosa of younger patients [5].

The onset and progression of oral mucositis (OM) depends considerably on several factors related to both the antineoplastic treatment and the patient's characteristics and individual susceptibility. Some of the treatment-related variables that can affect the prevalence and severity of mucositis are the drug type, dose and schedule of administration; the radiation field size and dose; and the concomitant exposure to chemotherapy and radiotherapy. Among the patient-related factors are age, body mass index, sex, hematological and biochemical alterations, changes in salivary production, poor oral health, and trauma to the mucosa [6,7].

Different scales have been proposed to diagnose OM and to assess its severity in children; for instance, the modified Oral Assessment Guide $(\mathrm{OAG})$ [7,8]. The modified OAG serves not only to screen for disruptions in the integrity of the oral mucosa, but it also allows for early identification of oral conditions, rendering therapeutic interventions timely and more clinically effective. This is critical to prevent OM from evolving to a more severe degree, in which patients can experience more intense painful symptoms and difficulties in speech, swallowing, chewing and, ultimately, in nourishing [3,9]. Accordingly, severe oral mucositis (SOM) may negatively impact the quality of life of children and adolescents and lead them to interrupt chemotherapy or radiotherapy, which considerably increases their risk of death [10].

The healthcare team should be aware of the specific moment during the antineoplastic treatment when SOM is more likely to develop, in order to optimize the therapeutic intervention and to improve the patient's quality of life [11]. Thus, in this study, we determined the occurrence of oral mucositis (OM) and severe oral mucositis $(\mathrm{SOM})$ in pediatric cancer patients undergoing antineoplastic treatment, and we further identified the factors associated with the onset of SOM.

\section{Material and Methods}

\section{Study Design and Sample Characteristics}

This was a longitudinal, prospective, observational study with a quantitative approach. The study location was the Pediatric Oncology Sector of Napoleão Laureano Hospital (HNL, in Portuguese), located in the city of João Pessoa, Paraíba State, northeastern Brazil. The state of Paraíba has an estimated population of 3,766,528 inhabitants, of which $1,305,858$ are aged between 0 and 10 years [12]. HNL is a state-wide reference center for cancer treatment, providing more than 40 thousand monthly consultations, exams, and surgeries [13].

The following eligibility criteria were considered: patients aged o to 19 years, of both sexes, undergoing antineoplastic treatment at HNL from November 2016 to July 2019, enrolled in the Brazilian Healthcare System, and that consented to participate in the study. At baseline (at diagnosis or prior to the start of treatment), the sample comprised a total of 85 patients. During follow-up, there were sample dropouts due to the transfer of patients to continue treatment in other locations $(n=17)$, home stay $(n=20)$, or due to death $(\mathrm{n}=11)$. Sixty-eight participants were assessed in the 2 nd week, then 49 in 5 th week and 37 in 10 th week. 


\section{Data Collection}

The following information was obtained the patients' medical charts: sociodemographic status and epidemiological information (sex, age, skin color and city of residence); data related to the underlying disease, type of antineoplastic treatment, time since the last treatment (chemotherapy and / or radiotherapy), class and type of chemotherapeutic drug, leukocyte and platelet count, and blood creatinine level.

The oral mucosa of study participants was assessed through the modified Oral Assessment Guide $(\mathrm{OAG})[14,15]$. This is a simple, easy-to-apply tool that was specifically designed to assess OM in children and that requires only 3 to 4 minutes to be completed [16]. The OAG includes eight items (voice, swallowing, lips, tongue, saliva, jugal / palate mucosa, labial mucosa, and gingiva), which are assessed based on an oral health impairment scale. Each item was assigned a score ranging from 1 to 3, as follows: 1 - Normal condition; 2 Mild to moderate alteration in the integrity of the oral epithelium or functional alterations; 3 - Severe impairment. The total score could range from 8 to 24 , with no cutoff point. In our study, a score of 3 for any item was indicative of the "Presence of SOM" (category 1). In contrast, OAG scores of 1 and 2 indicated “Absence of SOM" (category 0).

The work team was composed of calibrated examiners (Kappa index value of 0.74 - satisfactory agreement) and trained notetakers. The oral mucosal examinations were carried out at baseline (at diagnosis or prior to the start of treatment) and in the 2nd, 5th and 10th weeks of antineoplastic treatment. These timepoints were based on the estimated time for the onset of oral mucosal alterations in patients undergoing cancer therapy, which is up to two and a half months (10 weeks) [17].

\section{Definiton of Variables}

The response (dependent) variable "occurrence of severe oral mucositis" was categorized into "absent" (0) and "present" (1). The following explanatory variables were selected: age, sex, skin color, type of tumor, use of methotrexate, class of chemotherapeutic drugs used, type of drug in each class, leukocyte count, platelet count, and blood creatinine level. The variable age was categorized into "up to 10 years old" and "10 years or older" because study participants had a median age of 10 years.

Four classes of chemotherapeutic drugs were considered, according to the classification of the National Health Surveillance Agency, namely: alkylating agents, antimetabolites, natural products and miscellaneous. The present study focused on the class of antimetabolites, particularly methotrexate (MTX), since previous studies have shown that patients under chemotherapy regimen with antimetabolites are more likely to develop SOM $[7,8]$. MTX is one of the most widely used chemotherapeutic drugs, despite presenting stomatotoxicity and being frequently related to the occurrence of SOM [18].

The same reference values adopted by the HNL for leukocytes, platelets, and creatinine in pediatric cancer patients were also considered here in the analysis of hematological and biochemical parameters. The values fit one of three categories: 1: below the normal range; 2 : within the normal range; 3: above the normal range. The leukocyte count was categorized into 1 : less than $3,400 / \mathrm{mm}^{3} ; 2$ : between 3,400 to $9,500 / \mathrm{mm}^{3}$; $\mathrm{or}^{2}$ 3: greater than $9,500 / \mathrm{mm}^{3}$. The platelet count was categorized into 1 : less than $150,000 / \mathrm{mm}^{3} ; 2$ : between 150,000 and 450,000 / $\mathrm{mm}^{3}$; or 3: greater than 450,000 / $\mathrm{mm}^{3}$. Lastly, the creatinine level was categorized into 1: less than $0.4 \mathrm{mg} / \mathrm{dl}$; 2: between 0.4 and $1.3 \mathrm{mg} / \mathrm{dl}$; or 3: greater than $1.3 \mathrm{mg} / \mathrm{dl}$.

\section{Data Analysis}

The data were categorized, entered into a database, and analyzed descriptively by calculating the measures of central tendency and dispersion, as well as absolute and relative frequencies. Pearson's chi-square 
test was used to check for associations between the explanatory variables (age, hematological tumor diagnosis, use of antimetabolites, use of MTX, leukocyte count, platelet count and blood creatinine level) and the dependent variable "occurrence of SOM" (present or absent). The data were analyzed in SPSS version 21.0. program, considering a $5 \%$ significance level.

\section{Ethical Considerations}

This study was previously approved by the Research Ethics Committee of the Center for Health Sciences at the Federal University of Paraíba, under Protocol No. 046/17 (CAAE 642493 17.3.0000.5 188).

\section{Results}

In the period from November 2016 to June 2019, 85 children and adolescents assisted by the dental care team at the outpatient clinic and infirmary of the HNL Pediatric Oncology Sector were included in the study. Table 1 shows the sociodemographic characteristics of study participants. Most patients were males $(50.6 \%)$ and self-reported as mixed race $(51.8 \%)$. The participants' mean age was $9.5( \pm 5.4)$ years, with a median age of 10 years (minimum of 0 and a maximum of 19 years). Most of them were not from the state capital and lived in other cities across the state of Paraíba (72.9\%).

Table 1. Sociodemographic characteristics of pediatric cancer patients.

\begin{tabular}{lcc}
\hline \multicolumn{1}{c}{ Variables } & N & \% \\
\hline Sex & 42 & 49.4 \\
$\quad$ Female & 43 & 50.6 \\
$\quad$ Male & & \\
Age $(9.5 \pm 5.4$ Years $)$ & 44 & 51.8 \\
$\quad<10$ Years & 41 & 48.2 \\
$\quad \geq 10$ Years & & \\
Self-Reported Skin Color & 44 & 51.8 \\
$\quad$ Mixed Race & 35 & 41.2 \\
$\quad$ White & 3 & 3.5 \\
$\quad$ Black & 2 & 2.3 \\
$\quad$ Indigenous & 1 & 1.2 \\
$\quad$ Not Stated & & 21.2 \\
City of Residence & 18 & 72.9 \\
$\quad$ João Pessoa & 64 & 5.9 \\
\hline Other Cities in the State of Paraíba & 3 & \\
Cities in Other States &
\end{tabular}

The clinical and epidemiological data of the pediatric patients can be found in Table 2 . There was a higher prevalence of hematological neoplasms, of which Acute Lymphoid Leukemia (ALL) was the most common underlying disease (35.3\%). Most patients were submitted to exclusive chemotherapy (79.8\%).

Natural products were the most common class of chemotherapeutic drugs administered in the 1st week of antineoplastic treatment (94.8\%), especially vincristine, doxorubicin and daunorubicin. These drugs were used alone or in combination with other classes of drugs. During the follow-up period, natural products remained as the most frequently administered class, usually in combination with chemotherapeutic drugs from other classes such as MTX (antimetabolites) and cyclophosphamide (alkylants). 
Table 2. Clinical and epidemiological profile of pediatric cancer patients.

\begin{tabular}{|c|c|c|}
\hline Type of Tumor / Underlying Disease & $\mathbf{N}$ & $\%$ \\
\hline \multicolumn{3}{|l|}{ Hematological Tumor } \\
\hline Acute Lymphoblastic Leukemia & 30 & 35.3 \\
\hline Acute Myeloid Leukemia & 11 & 13.0 \\
\hline Non-Hodgkin's Lymphoma & 9 & 10.6 \\
\hline Hodgkin's Lymphoma & 7 & 8.2 \\
\hline Total & 57 & 67.1 \\
\hline \multicolumn{3}{|l|}{ Solid Tumor } \\
\hline Osteosarcoma & 8 & 9.4 \\
\hline Wilms Tumor & 4 & 4.7 \\
\hline Rhabdomyosarcoma & 4 & 4.7 \\
\hline Neuroblastoma & 3 & 3.5 \\
\hline Testicular Tumor & 3 & 3.5 \\
\hline Central Nervous System Tumor & 2 & 2.3 \\
\hline Breast Cancer & 1 & 1.2 \\
\hline Melanoma & 1 & 1.2 \\
\hline Ovarian Tumor & 1 & 1.2 \\
\hline Ewing's Sarcoma & 1 & 1.2 \\
\hline Total & 28 & 32.9 \\
\hline \multicolumn{3}{|l|}{ Antineoplastic Therapy } \\
\hline Exclusive Chemotherapy & 67 & 79.8 \\
\hline Chemotherapy and Surgery & 11 & 13.1 \\
\hline Chemotherapy and Radiotherapy & 7 & 7.1 \\
\hline \multicolumn{3}{|c|}{ Class of Chemotherapeutic Drug Administered in the $1^{\text {st }}$ Week of Treatment* } \\
\hline Natural Products & 79 & 94.8 \\
\hline Antimetabolites & 27 & 32.4 \\
\hline Alkylants & 15 & 17.7 \\
\hline Miscellaneous & 9 & 10.8 \\
\hline
\end{tabular}

*Patients were administered chemotherapeutic drugs of more than one class.

The occurrence and severity of OM were assessed by the modified OAG. Table 3 shows that OM was most frequent (60\%) 2 weeks after the start of treatment and that $32.3 \%$ of the patients developed SOM in the 2nd week.

Table 3. The occurrence and severity of oral mucositis in pediatric cancer patients, per week of antineoplastic treatment.

\begin{tabular}{|c|c|c|c|c|c|c|}
\hline \multirow[t]{2}{*}{ Variables } & \multicolumn{2}{|c|}{ Presence } & \multicolumn{2}{|c|}{ Absence } & \multicolumn{2}{|c|}{ Total } \\
\hline & $\mathrm{N}$ & $\%$ & $\mathrm{~N}$ & $\%$ & $\mathrm{~N}$ & $\%$ \\
\hline \multicolumn{7}{|l|}{ Oral Mucositis } \\
\hline 2nd Week & 41 & 60.0 & 27 & 40.0 & 68 & 100.0 \\
\hline 5th Week & 20 & 40.9 & 29 & 59.1 & 49 & 100.0 \\
\hline 10th Week & 16 & 43.2 & 21 & 56.8 & 37 & 100.0 \\
\hline \multicolumn{7}{|l|}{ Severe Oral Mucositis } \\
\hline 2nd Week & 22 & 32.3 & 46 & 67.7 & 68 & 100.0 \\
\hline 5th Week & 17 & 34.7 & 32 & 65.3 & 49 & 100.0 \\
\hline 10th Week & 11 & 29.7 & 26 & 70.3 & 37 & 100.0 \\
\hline
\end{tabular}

Table 4 describes the absolute and percent frequencies of SOM for each study variable per week of antineoplastic treatment. OM was most frequently observed in patients younger than 10 years $(42.9 \%)$ in the 10th week of antineoplastic treatment. In the 2 nd week of follow-up, the occurrence of SOM was greater in patients with hematological tumors $(31.4 \%)$ compared to those with solid tumors. SOM cases were more 
frequent among patients undergoing chemotherapy with antimetabolites after the 5 th week (31.6\%) and 10th week $(43.5 \%)$ of treatment. In all follow-up timepoints, there was a higher predominance of SOM in patients not treated with MTX, although such differences were not statistically significant.

As for hematological and biochemical parameters, our study showed that leukopenic patients had a higher frequency of SOM (43.8\%) in the 10th week of antineoplastic treatment. SOM cases prevailed in thrombocytopenic children and adolescents in the 2 nd week (30.4\%) and 10th week (50.0\%) of treatment. Patients with a creatinine level within the range of $0.4-1.3 \mathrm{mg} / \mathrm{dl}$ had a higher incidence of SOM in the 2 nd week $(23.9 \%)$ and 5 th week $(31.0 \%)$ of treatment. Overall, there was no relationship between any of the hematological and biochemical parameters and the occurrence of SOM throughout the duration of treatment.

\section{Discussion}

HNL is the reference center for cancer treatment in the state of Paraíba, northeastern Brazil. Hence, the results presented herein describe the state-wide epidemiological profile of pediatric cancer patients [13].

Our findings showed that most children and adolescents with cancer were males, which is consistent with other reports in northern Brazil (64.4\% prevalence of males) [19] and in Hong Kong (69 children, 64\% prevalence of males) [20].

The HNL Pediatric Oncology Sector admits patients aged o to 19 years. According to their medical records, the mean age of the patients in our study was 9.5 years $( \pm 5.4$ years $)$ and a median age of 10 years, which is also in line with the Hong Kong study [20]. Here, the highest prevalence of cancer was observed in patients aged up to 10 years, corroborating the findings of a study carried out in oncology services in the Brazilian states of Rio Grande do Sul and Piauí [19].

Self-reported mixed race was predominant $(51.8 \%)$ in our study sample. This percentage is comparable to that of a study with 689 children admitted to a referral hospital in Teresina, PI, Brazil, which showed that $58.0 \%$ of the pediatric cancer patients were self-reported mixed-race [21]. Intriguingly, the 2010 demographic census of the Brazilian Institute of Geography and Statistics indicated that the Brazilian population aged o to 19 years is predominantly white [22]. A possible explanation for the predominance of mixed-race children and adolescents, in both studies, may be that such a population is more frequently assisted by the Brazilian Healthcare System (BHS). A previous study found that black and mixed-race individuals, with less schooling and lower family income per capita, were more likely to use the BHS. Hence, groups from poorer socioeconomic backgrounds comprise most of the BHS users [23].

In our study, most participants were reportedly not from the state capital (72.9\%), João Pessoa, and a small percentage of them had come from other states of Brazil (3.5\%) for treatment. Access to healthcare services is a critical aspect of cancer care, particularly in terms of geographic accessibility, which remains a major difficulty faced by healthcare users in need of antineoplastic treatment. Due to regional accessibility issues, some patients and family members or caregivers cannot always travel to the places where healthcare facilities are located [24]. This is also seen in other countries, where healthcare services for the diagnosis and treatment of childhood cancer are predominantly restricted to a few tertiary care centers located in major cities. This configuration does not favor an early diagnosis of childhood cancer and contributes to an increased risk of death $[25,26]$. In a previous study, pediatric cancer patients from the state of Paraíba and / or their family members or caregivers reported they were provided with transportation to/from the HNL Pediatric Oncology Sector by the municipal administration [27]. 
Table 4. Factors associated with the occurrence of severe oral mucositis in pediatric cancer patients, per week of antineoplastic treatment.

\begin{tabular}{|c|c|c|c|c|c|c|c|c|c|c|c|c|}
\hline \multirow{4}{*}{ Variables } & \multicolumn{12}{|c|}{ Occurrence of Severe Oral Mucositis Per Week of Treatment } \\
\hline & \multicolumn{4}{|c|}{ 2nd Week } & \multicolumn{4}{|c|}{ 5th Week } & \multicolumn{4}{|c|}{ 10th Week } \\
\hline & \multicolumn{2}{|c|}{ Present } & \multicolumn{2}{|c|}{ Absent } & \multicolumn{2}{|c|}{ Present } & \multicolumn{2}{|c|}{ Absent } & \multicolumn{2}{|c|}{ Present } & \multicolumn{2}{|c|}{ Absent } \\
\hline & $\mathrm{N}$ & $\%$ & $\mathrm{~N}$ & $\%$ & $\mathrm{~N}$ & $\%$ & $\mathrm{~N}$ & $\%$ & $\mathrm{~N}$ & $\%$ & $\mathrm{~N}$ & $\%$ \\
\hline \multicolumn{13}{|l|}{ Age } \\
\hline$<10$ Years & 9 & 27.3 & 24 & 72.7 & 6 & 31.6 & 13 & 68.4 & 6 & 42.9 & 8 & 57.1 \\
\hline$\geq 10$ Years & 13 & 37.1 & 22 & 62.9 & 11 & 36.7 & 19 & 63.3 & 5 & 21.8 & 18 & 78.2 \\
\hline p-value & \multicolumn{4}{|c|}{0.385} & \multicolumn{4}{|c|}{0.715} & \multicolumn{4}{|c|}{0.173} \\
\hline \multicolumn{13}{|l|}{ Hematological Tumor } \\
\hline Yes & 16 & 31.4 & 35 & 68.6 & 14 & 37.9 & 23 & 62.1 & 9 & 32.2 & 19 & 67.8 \\
\hline No & 6 & 35.3 & 11 & 64.7 & 3 & 25.0 & 9 & 75.0 & 2 & 22.3 & 7 & 77.7 \\
\hline p-value & \multicolumn{4}{|c|}{0.765} & \multicolumn{4}{|c|}{0.417} & \multicolumn{4}{|c|}{0.571} \\
\hline \multicolumn{13}{|l|}{ Use of Antimetabolites(a) } \\
\hline Yes & 6 & 27.3 & 16 & 72.7 & 6 & 31.6 & 13 & 68.4 & 4 & 43.5 & 13 & 56.5 \\
\hline No & 11 & 33.3 & 22 & 66.7 & 6 & 26.1 & 17 & 73.9 & 6 & 37.5 & 10 & 62.5 \\
\hline p-value & \multicolumn{4}{|c|}{0.581} & \multicolumn{4}{|c|}{0.695} & \multicolumn{4}{|c|}{0.383} \\
\hline \multicolumn{13}{|l|}{ Use of Methotrexate(a) } \\
\hline Yes & 3 & 17.7 & 14 & 82.3 & 3 & 25.0 & 9 & 75.0 & 2 & 18.2 & 9 & 81.8 \\
\hline No & 14 & 36.9 & 24 & 63.1 & 9 & 30.0 & 21 & 70.0 & 8 & 36.4 & 14 & 63.6 \\
\hline p-value & \multicolumn{4}{|c|}{0.155} & & & & & & & & \\
\hline Leukocyte Count $(\mathrm{b})$ & & & & & & & & & & & & \\
\hline$<3,400 / \mathrm{mm}^{3}$ & 10 & 32.3 & 21 & 67.7 & 4 & 25.0 & 12 & 75.0 & 7 & 43.8 & 9 & 56.2 \\
\hline $3,400-9,500 / \mathrm{mm}^{3}$ & 6 & 33.3 & 12 & 66.7 & 8 & 44.4 & 10 & 55.6 & 2 & 13.3 & 13 & 86.7 \\
\hline$>9,500 / \mathrm{mm}^{3}$ & 2 & 15.4 & 11 & 84.6 & 3 & 25.0 & 9 & 75.0 & 1 & 25.0 & 3 & 75.0 \\
\hline p-value & & & & & & & & & & & & \\
\hline Platelet Count(c) & & & & & & & & & & & & \\
\hline$<150,000 / \mathrm{mm}^{3}$ & 7 & 30.4 & 16 & 69.6 & 3 & 27.3 & 08 & 72.7 & 6 & 50.0 & 6 & 50.0 \\
\hline $150,000-450,000 / \mathrm{mm}^{3}$ & 10 & 30.3 & 23 & 69.7 & 9 & 32.1 & 19 & 67.9 & 4 & 21.1 & 15 & 78.9 \\
\hline$>450.000 / \mathrm{mm}^{3}$ & 1 & 16.7 & 5 & 83.3 & 2 & 33.3 & 4 & 66.7 & $\mathrm{O}$ & 0.0 & 4 & 100.0 \\
\hline p-value & & & & & & & & & & & & \\
\hline Blood Creatinine Level(d) & & & & & & & & & & & & \\
\hline$<0.4 \mathrm{mg} / \mathrm{dl}$ & 7 & 41.2 & 10 & 58.8 & 5 & 38.5 & 8 & 61.5 & 4 & 44.4 & 5 & 55.6 \\
\hline $0.4-1.3 \mathrm{mg} / \mathrm{dl}$ & 10 & 23.9 & 32 & 76.2 & 9 & 31.0 & 20 & 69.0 & 5 & 20.8 & 19 & 79.2 \\
\hline$>1.3 \mathrm{mg} / \mathrm{dl}$ & o & 0.0 & 0 & 0.0 & 0 & 0.0 & 0 & 0.0 & $\mathrm{O}$ & 0.0 & $\mathrm{O}$ & 0.0 \\
\hline p-value & & & & & & & & & & & & \\
\hline
\end{tabular}

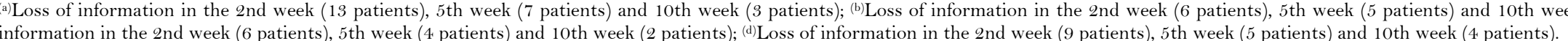


Our findings indicated a higher prevalence of hematological neoplasms (66.7\% of cases) in the study sample. This is consistent with what was found in Hong Kong, where hematological neoplasms were more prevalent than solid tumors [20]. Evidence has shown that while hematological tumors account for only $6.2 \%$ of neoplasms in all age groups, they are the most prevalent type of tumor during childhood worldwide [28, 29].

Acute Lymphoblastic Leukemia (ALL) was the most frequent neoplasm in our study sample, affecting 30 children and adolescents (35.3\%). These findings corroborate those of the literature, which shows that ALL is more prevalent in children aged o to 14 years [30]. The onset of ALL in patients within this age range can be explained by an impaired development of the immune system, which renders the patient more susceptible to severe infectious conditions [31].

Other neoplasms observed in the sample included Acute Myeloid Leukemia (AML) (13\%), Hodgkin's Lymphoma (8.2\%) and Non-Hodgkin's Lymphoma (10.6\%). AML cases account for approximately $18 \%$ of leukemia cases worldwide and are more prevalent in the neonatal period. Hodgkin's Lymphoma corresponds to $5 \%$ of childhood neoplasms, with a higher prevalence in individuals under 14 years of age. Studies have shown that Hodgkin's and Non-Hodgkin's Lymphomas are associated with immunodeficiency and infectious process caused by the Epstein-Barr virus and cytomegalovirus [32].

Our study and another one carried out in the state of Paraná [33] revealed that chemotherapy was the most widely used therapeutic approach among pediatric cancer patients, either alone or in combination with other treatments. Chemotherapy, together with radiotherapy and surgery are the main modalities currently available to treat childhood cancer [34]. In our study sample, all patients undergoing radiotherapy were also submitted to chemotherapy. The literature points out that radiotherapy should be used with caution and that it is being gradually less indicated in the treatment of children and adolescents due to its late side effects [35].

The antineoplastic treatment, particularly chemotherapy, has been implicated in the onset of oral manifestations in children and adolescents with cancer [36]. For instance, the risk of developing OM is increased during ALL treatment with antimetabolites such as MTX (which impairs cell metabolism, including cell division) or with pro- and anti-inflammatory therapies based on cytokines or pro-LL37 [36]. As shown in a previous study, antimetabolites have been widely prescribed in the HNL reference center. The representative drug of this class is MTX, a chemotherapeutic agent frequently administered to pediatric patients with cancer, especially to non-metastatic and older patients, due to their lower sensitivity to adverse effects [7].

Our study showed that $32.4 \%$ of patients were administered antimetabolites in the 1 st week of antineoplastic treatment. Choosing the chemotherapeutic drug class in the early stages of treatment is critical, as the development of $\mathrm{OM}$ is known to be most significant in the first ten days of cancer therapy [37]. Herein, the occurrence of OM and SOM ranged from 40.9 to $60 \%$ and from 29.7 to $32.3 \%$, respectively. The first symptoms of $\mathrm{OM}$ begin in approximately 10 days of drug administration, with lesions lasting 6 days on average [37]. This explains the higher incidence of OM and SOM observed in sample subjects in the 2 nd week of treatment.

The modified OAG considers oral conditions that are not commonly addressed in other assessment tools [17]. For example, the presence of SOM is not only indicated by ulcerative lesions, but also by changes in the voice, absence of saliva and dryness of the lip vermilion. This may explain the higher incidence of OM and SOM observed here compared with that of studies using other tools such as the WHO scale [4,41].

The onset of SOM has been associated with external factors and patient characteristics. In our study, there was no association between the occurrence of SOM and the participant's age. However, studies have 
shown that younger patients are more likely to experience adverse effects of chemotherapy, such as OM [17,38]. In line with our findings, a previous study carried out in the HNL reference center showed no significant association between SOM occurrence and the participant's age. However, the authors pointed out that patients older than 10 years had lesions lasting 1.4 times longer than younger patients [7]. The influence of age on the severity of mucositis is reasoned to be a result of the difference in tissue maturity, given that younger individuals have intense cell turnover, which contributes to greater drug susceptibility and faster regeneration [5]. Here, the small number of patients evaluated throughout the follow-up period and the sample losses may have not allowed detecting significant differences between the occurrence of SOM and the participant's age.

Another study carried out in the HNL reference center demonstrated that children undergoing chemotherapy for hematological neoplasms developed OM more frequently [11]. Patients with hematological neoplasms were shown to have a seven-fold increased risk of presenting OM lesions when compared to those with solid or central nervous system tumors [6]. Despite this, in our study, there was no association between the occurrence of SOM and the type of tumor throughout the whole follow-up period.

Individuals with hematological tumors are most often treated with antimetabolites, which are the drugs most stomatotoxic to the oral mucosa [18]. The modified OAG data revealed that the chemotherapeutic regimen affected patient swallowing as well as the labial and jugal mucosa, palate, and gingiva, especially in patients with hematological tumors [16]. However, the chemotherapeutic drugs of choice in the treatment of pediatric cancer are not equally stomatotoxic. MTX and 5-fluorouracil, both antimetabolites, are the drugs most reported to cause alterations in the oral mucosa $[8,18]$. Patients whose therapeutic regimens do not include MTX tend to have a lower occurrence of SOM [7]. Unexpectedly, this study found no association between the use of MTX and the occurrence of SOM during ten weeks of treatment. Preventive oral care measures are known to mitigate the occurrence and progression of $\mathrm{OM}$ even in patients being administered high drug doses [6], which could partially explain the lack of association observed herein.

The implementation of a systemic prophylactic protocol for patients undergoing chemotherapy could mitigate drug-related adverse effects. The HNL protocol includes the use of cytoprotectors, for example, amifostine, which provides less liver, cardiac, pulmonary, and oral mucosal damage [7]. Of note, we did not test any associations between the type of tumor (hematological or solid) and the outcome of interest (presence or absence of $\mathrm{OM}$ ) because the protocols were different and were not examined here. This could also explain the lack of association between the use of antimetabolites, such as MTX, and the occurrence of SOM.

Following the cancer diagnosis, children should be ideally assisted by a dentist working in collaboration with the pediatric oncology team, so that dental care preferably precedes the antineoplastic treatment to prevent complications and delays [29]. A study carried out in the HNL Pediatric Oncology Sector surveyed patient access to the hospital and their satisfaction with dental care services. The authors reported that most patients did not experience difficulties when seeking dental care in healthcare facilities close to their households [27].

While there is evidence suggesting that chemotherapy may affect blood cells and thereby cause leukopenia and thrombocytopenia [39,40], our data showed no association between the patients' hematological and biochemical parameters and the occurrence of SOM at any timepoint. Studies show that low leukocyte and platelet counts increase the risk of developing mucositis. This may be because, once the neutrophil count is reduced, the host immune response becomes less efficient to adequately manage the cytotoxic effects of the chemotherapeutic drug against the oral mucosa [39,40]. Neutropenic patients have a 7.5 -fold greater risk of 
developing OM [6], especially if their leukocyte count is below 9,500/ $\mathrm{mm}^{3}$ [11]. SOM causes loss of tissue integrity, thus increasing the patient's risk of bacterial infection, sepsis, and death [41].

The association between platelet count and the occurrence of SOM remains conflicting. While patients with thrombocytopenia are expected to be more likely to develop SOM, our findings showed no significant association between these variables. On the other hand, a study carried out in the HNL reference center reported that high platelet count may be a risk factor for developing SOM. The authors further reported that the high platelet count in participating patients resulted from a transfusion of platelet concentrate and that such pediatric patients were immunocompromised [11].

In our study, creatinine levels were not related to the occurrence of SOM. Creatinine is a bloodcirculating byproduct directly involved with glomerular filtration and that serves as a renal function marker. Several chemotherapeutic drugs (e.g., cisplatin, epirubicin, cyclophosphamide, paclitaxel and melphalan) are nephrotoxic and have been shown to alter blood creatinine and urea levels [42]. Thus, the use of drugs that may alter renal function contributes to drug depuration issues and increased body toxicity, which may also favor the development of SOM [43].

Childhood cancer is a rare condition when compared to the prevalence of neoplasms in adults. Therefore, cancer research in children and adolescents involves difficulties in terms of patient randomization. The sampling process in our study was defined for convenience, and the inclusion criteria consisted of admission to the HNL Pediatric Oncology Sector and consent participation. Another limitation of the present study was the loss of follow-up due to continuity of treatment in other locations, home stay, or due to death. However, while the loss of follow-up may compromise the internal validity and conclusions of our study, this is a frequent shortcoming in pediatric cancer research.

Study participants had heterogeneous characteristics and were submitted to different therapeutic protocols based on their underlying diseases, which could render the extrapolation of results potentially biased. However, grouping children and adolescents into two groups (solid tumors and hematological neoplasms) was an effective strategy used in our study to overcome this limitation. Moreover, there are other explanatory variables, which were not included, that may be associated with the occurrence of OM, such as genetic factors, oral hygiene condition, and the dose of chemotherapeutic drugs.

Taken altogether, the findings presented herein may contribute to a better understanding of the factors associated with the occurrence and severity of OM, particularly of SOM, in pediatric cancer patients. Our results reinforce the need for clinical conduct of oral health surveillance, especially in the 2 nd week of antineoplastic treatment, when children and adolescents are more likely to develop this comorbidity.

\section{Conclusion}

The occurrence of oral mucositis in pediatric cancer patients was significant, especially in the 2 nd week of antineoplastic treatment. Severe oral mucositis was more prevalent in the 5 th week of treatment and was not associated with any of the study variables.

\section{Authors' Contributions}

$\begin{array}{lll}\text { HFP } & \text { (D) O000-0002-6622-511X } & \text { Methodology, Investigation, Formal Analysis and Writing - Review and Editing. } \\ \text { PMMB } & \text { (D) 0000-0002-9705-8959 } & \text { Methodology, Investigation, Formal Analysis and Writing - Review and Editing. } \\ \text { VBS } & \text { (D) 0000-0001-9960-6616 } & \text { Investigation, Formal Analysis and Writing - Review and Editing. } \\ \text { ILAR } & \text { (D) 0000-0001-6538-6811 } & \begin{array}{l}\text { Conceptualization, Methodology, Formal Analysis and Writing - Review and } \\ \text { Editing. }\end{array}\end{array}$


EBMS (D) 0000-0002-9119-4079 Methodology, Supervision and Writing - Review and Editing.

SAS (D) 0000-0002-3254-9036 Methodology, Supervision and Writing - Review and Editing.

AMGV (D) 0000-0001-8460-3981 Conceptualization, Methodology, Investigation, Formal Analysis and Writing Review and Editing.

All authors declare that they contributed to critical review of intellectual content and approval of the final version to be published.

\section{Financial Support}

National Council of Scientific and Technological Development (CNPq) - Brazil (Grant No. 407394/2016-8).

\section{Acknowledgments}

The authors HFP, PMMB and VBS wish to thank for Institutional Program for Scientific Initiation Scholarship (PIBIC/CNPq) and the Napoleão Laureano Hospital for allowing this study was performed in the Pediatric Oncology Sector.

\section{Conflict of Interest}

The authors declare no conflicts of interest.

\section{References}

[1] Brasil. Instituto Nacional do Câncer. Câncer Infantojuvenil. Instituto Nacional de Câncer José Alencar Gomes da Silva. Coordenação de Prevenção e Vigilância. Available from: https://www.inca.gov.br/tipos-de-cancer/cancerinfantojuvenil. [Accessed on January 10, 2020] [In Portuguese].

[2] Stewart BW, Wild CP. World Cancer Report 2014. Lyon: International Agency for Research on Cancer; 2014. 632p.

[3] Sasada INV, Cancino CMH, Petersen RC, Hellwing I, Dillenburg CS. Prevention of stomatological complications in pediatric oncology. RFO UPF 2015; 20(1):105-9.

[4] Velten DB, Zandonade E, Miotto MHMB. Prevalence of oral manifestations in children and adolescents with cancer submitted to chemotherapy. BMC Oral Health 2016; 1(16):107-15. https://doi.org/10.1186/s12903-016-0300-2

[5] Pinto MTF, Soares LG, DG Silva, Tinoco EMB, Falabella MEV. Prevalence of oral manifestations in children and young patients submitted to chemotherapy. Rev Pesqui em Saúde 2014; 14(1):45-8.

[6] Allen G, Logan R, Revesz T, Keefe D, Gue S. The prevalence and investigation of risk factors of oral mucositis in a pediatric oncology inpatient population: a prospective study. J Pediatr Hematol Oncol 2018; 40(1):15-21. https://doi.org/10.1097/MPH.0000000000000970

[7] Damascena LCL, de Lucena NNN, Ribeiro ILA, de Araujo TLP, de Castro RD, Bonan PRF, et al. Factors contributing to the duration of chemotherapy-induced severe oral mucositis in oncopediatric patients. Int J Environ Res Public Health 2018; 15(6):1153. https://doi.org/10.3390/ijerph15061153

[8] Ribeiro ILA, Lima Neto EA, Valença AMG. Chemotherapy in pediatric oncology patients and the occurrence of oral mucositis. Int J Clin Pediatr Dent 2019; 12(4):261-7. https://doi.org/10.5005/jp-journals-10005-1633

[9] Villa A, Sonis S. Mucositis: pathobiology and management. Curr Opin Oncol 2015; 27(3):159-64. https://doi.org/10.1097/CCO.0000000000000180

[10] Dean JA, Welsh LC, Wong KH, Aleksic A, Dunne E, Islam MR, et al. Normal Tissue Complication Probability (NTCP) modelling of severe acute mucositis using a novel oral mucosal surface organ at risk. Clin Oncol 2017; 29(4):263-73. https://doi.org/10.1016/j.clon.2016.12.001

[11] Damascena LCL, de Lucena NNN, Ribeiro ILA, Pereira TL, Lima-Filho LMA, Valença AMG. Mucositis in pediatric cancer patients: survival analysis and predictive factors. Int J Environ Res Public Health 2020; 17(4):1235. https://doi.org/10.3390/ijerph 17041235

[12] Instituto Brasileiro de Geografia e Estatística. Paraíba. Available from: https://cidades.ibge.gov.br/brasil/pb. [Accessed on March 23, 2020]. [In Portuguese]

[13] Paraíba. Tratamento de câncer ofertado na PB é destaque na imprensa nacional. Available from: http://paraiba.pb.gov.br/tratamento-decancer-ofertadona-paraiba-e-destaque-na-imprensa-nacional/. [Accessed on June 19, 2019]. [In Portuguese]

[14] Eilers J, Berger AM, Petersen MC.Development, testing, and application of the oral assessment guide. Oncol Nurs Forum 1988; 15(3):325-30.

[15] Cheng KKF, Chang AM, Yuenc MP. Prevention of oral mucositis in paediatric patients treated with chemotherapy: a randomized crossover trial comparing two protocols of oral care. Eur J Cancer 2004; 40(8):1208-16. https://doi.org/10.1016/j.ejca.2003.10.023 
[16] Ribeiro ILA, Silva SM, Limeira RRT, Bonan PRF, Valença AMG, Neto EAL, et al. Differences between the oral changes presented by patients with solid and hematologic tumors during the chemotherapeutic treatment. J Appl Oral Sci 2019; 28:e.20190020. https://doi.org/10.1590/1678-7757-2019-0020

[17] Cheng KK, Lee V, Li CH, Goggins W, Thompson DR, Yuen HL, et al. Incidence and risk factors of oral mucositis in paediatric and adolescent patients undergoing chemotherapy. Oral Oncol 2011; 47(3):153-62. https://doi.org/10.1016/j.oraloncology.2010.11.019

[18] Cheng KK, Lee V, Li CH, Yuen HL, Epstein JB. Oral mucositis in pediatric and adolescent patients undergoing chemotherapy: the impact of symptoms on quality of life. Support Care Cancer 2012; 20(1):2335-42. https://doi.org/10.1007/s00520-011-1343-1

[19] Mutti CF, Cruz VG, Santos LF, Araújo D, Cogo SB, Neves ET. Clinical and epidemiological profile of children and adolescents with cancer in an oncology service. Rev Bras Cancerol 2018; 64(3):293-9. https://doi.org/10.32635/2176-9745.RBC.2018v64n3.26

[20] Kung AYH, Zhang S, Zheng LW, Wong GHM, Chu CH. Oral health status of Chinese paediatric and adolescent oncology patients with chemotherapy in Hong Kong: a pilot study. Open Dent J 2015; 9(1):21-30. https://doi.org/10.2174/1874210601509010021

[21] Pedrosa AO, Lira Filho R, Santos FJL, Gomes RNS, Monte LRS, Portela NLC. Clinical and epidemiological profile of pediatric oncology clients served in a Piauí referral hospital. Rev Interdiscip 2015; 8(3):12-21.

[22] Brasil. Ministério da Saúde. Instituto Nacional do Câncer. Relatório Anual. 2010. Available from: https://www.inca.gov.br/sites/ufu.sti.inca.local/files//media/document//relatorio-gestao-inca-2010.pdf. [Accessed on March 15, 2020]. [In Portuguese]

[23] Ribeiro, MCSA, Barata RB, Almeida MF, Silva ZP. Sociodemographic profile and utilization patterns of the public health care system (SUS) - PNAD 2003. Ciênc Saúde Coletiva 2003; 11(4):1011-22. https://doi.org/10.1590/S1413-81232006000400022

[24] Grabois MF, Oliveira EXG, CarvalhoMS. Access to pediatric cancer care in Brazil: mapping origin-destination flows. Rev Saúde Pública 2013; 47(2):368-78. https://doi.org/10.1590/So034-8910.2013047004305

[25] Ganguly S, Kinsey S, Bakhshi S. Childhood cancer in India. Cancer Epidemiol 2020; $2020: 101679$. https://doi.org/10.1016/j.canep.2020.101679

[26] Aristizabal RP, Zaidi A, Gagnepain-Lacheteau A, Ribeiro RC, Bravo LE. Childhood cancer survival disparities in a universalized health system in Cali, Colombia. Pediatr Hematol Oncol J 2019; 3(4):79-87. https://doi.org/10.1016/j.phoj.2019.01.001

[27] Carneiro TV, Ribeiro ILA, Neto EAL, Valença AMG. Access to and satisfaction with oral health care from the perspective of pediatric cancer patients and their caregivers. Pesqui Bras Odontopediatria Clin Integr 2015; 15(1):171-81. https://doi.org/10.4034/PBOCI.2015.151.19

[28] Chizuka A, Suda M, Shibata T, Kusumi E, Hori A, Hamaki T, et al. Difference between hematological malignancy and solid tumor research articles published in four major medical journals. Leukemia 2006; 20(10):2655-7. https://doi.org/10.1038/sj.leu.2404369

[29] Ribeiro ILA, Valença AMG, Bonan PRF. Dentistry in Pediatric Oncology. 2nd ed. João Pessoa: Editora Ideia; 2018. Available from: https://www.researchgate.net/publication/301627894_Odontologia_na_Oncologia_Pediatrica/ citation/download. [Accessed on March 10, 2019].

[30] Hanna LMO, Araújo RJG, Santos MTBR, Filho GGA. Pediatric cancer: epidemiologic profile of attended children in a reference center in the state of Para. J Res Dent 2017; 4(3):100-7. https://doi.org/10.19177/jrd.v4e32016100-107

[31] Wang R, Wiemels JL, Metayer C, Morimoto L, Francis SS, Kadan-Lottick N, et al. Cesarean section and risk of childhood acute lymphoblastic leukemia in a population-based, record-linkage study in California. Am J Epidemiol 2017; 185(2): 96-105. https://doi.org/10.1093/aje/kww 153

[32] Saki J, Tavakoli S, Pedram M. Seroprevalence and molecular evaluation of toxoplasmosis in children with cancer in Khuzestan province, Southwest of Iran. J Parasit Dis 2017; 41:947-51. https://doi.org/10.1007/s 12639-017-0916-4

[33] Bauer DFV, Ferrari RAP, Reis TB, Tacla MTGM. Children with cancer: characterization of hospitalization in a public teaching hospital. Biol Saúde 2015; 1(36):9-16. https://doi.org/10.5433/1679-0367.2015v36n1Suplp9

[34] Handgretinger R, Schlegel P. Emerging role of immunotherapy for childhood cancers. Chin Clin Oncol $2018 ; 7(2): 14$. https://doi.org/10.21037/cco.2018.04.06

[35] Brasil. Instituto Nacional do Câncer. Tipo do Câncer Infantil. Available from: http://www2.inca.gov.br/wps/wcm/connect/tiposdecancer/site/home/infantil. [Accessed on March 27, 2020]. [In Portuguese]

[36] Ye Y, Carlsson G, Agholme MB, Karlsson-Sjöberg J, Yucel-Lindberg T, Pütsep K, et al. Pretherapeutic plasma proand anti- inflammatory mediators are related to high risk of oral mucositis in pediatric patients with acute leukemia: a prospective cohort study. PLoS One 2013; 5(8):e64918. https://doi.org/10.1371/journal.pone.0064918

[37] Lopes IA, Nogueira DN, Lopes IA. Oral manifestations of chemotherapy in children from a cancer treatment center. Pesqui Bras Odontopediatria Clin Integr 2012; 12(1):113-9. https://doi.org/10.4034/PBOCI.2012.121.18 
[38] Cheng KKF, Chang AM, Yuen MP. Prevention of oral mucositis in paediatric patients treated with chemotherapy: a randomised crossover trial comparing two protocols of oral care. Eur J Cancer 2004; 40(8):1208-16. https://doi.org/10.1016/j.ejca.2003.10.023

[39] Patussi C, Sassi LM, Munhoz EC, Zanicotti RT, Schussel JL. Clinical assessment of oral mucositis and candidiasis compare to chemotherapic nadir in transplanted patients. Braz Oral Res 2014; 28(1):1-7. https://doi.org/10.1590/1807-3107bor-2014.vol28.0050

[40] Suresh AV, Varma PP, Sinha S, Deepika S, Raman R, Srinivasan M, et al. Risk-scoring system for predicting mucositis in patients of head and neck cancer receiving concurrent chemoradio-therapy [Rssm-Hn]. J Cancer Res Ther 2016; 6(4):448-51. https://doi.org/10.4103/0973-1482.77100

[41] Nascimento PBL, Santos LCO, Carvalho CN, Alves CAL, Lima SM, Cabral MMS. Oral manifestations in hospitalized children and adolescents subjected to antineoplastic therapy. Pesqui Bras Odontopediatria Clin Integr 2013; 3(13):279-85. https://doi.org/10.4034/PBOCI.2013.133.09

[42] Silva SR, Ávila FF, Soares MBO. Hematological and biochemical serum profiles of patients undergoing antineoplastic chemotherapy. Rev Enferm Atenção Saúde 2013; 2(2):32-45.

[43] Yang SL, Zhao FY, Song H, Shen DY, Xu XJ. Methotrexate associated renal impairment is related to delayed elimination of high-dose methotrexate. Scientific World J 2015; 2015:751703. https://doi.org/10.1155/2015/751703 